\title{
Morphological diversification among island populations of intertidal mites (Acari, Oribatida, Fortuyniidae) from the Galápagos archipelago
}

\author{
Tobias Pfingstl $^{1}$ (D) $\cdot$ Julia Baumann $^{1}$ (D)
}

Received: 31 March 2017/Accepted: 9 June 2017/Published online: 20 June 2017

(C) The Author(s) 2017. This article is an open access publication

\begin{abstract}
The intertidal oribatid mite species Alismobates galapagoensis and Litoribates caelestis occur on the archipelago of Galápagos. To test for morphological variation between populations of different islands, a comprehensive morphometric study was performed. Four A. galapagoensis populations from the islands Bartolomé, Isabela, Santa Cruz and San Cristobal, as well as two L. caelestis populations from Bartolomé and Santa Cruz were investigated. The $L$. caelestis populations did not show any significant differences whereas the A. galapagoensis populations exhibited clear divergences indicating speciation. Differences in overall size of A. galapagoensis apparently followed a gradient from East to West, with specimens from San Cristóbal being the largest and individuals from Bartolomé and Isabela being the smallest. Apart from size, significant shape differences were found in the epimeral region and females showed stronger variation among islands than males. The degree of morphological divergence seems to correlate with geographic distance, i.e. populations from islands located closer to each other showed fewer differences than populations from distant islands. Based on this correlation we suggest that transport between islands has happened mainly by drifting on ocean currents.
\end{abstract}

Keywords Speciation · Multivariate analyses $\cdot$ Dispersal $\cdot$ Alismobates $\cdot$ Litoribates

\section{Introduction}

The family of Fortuyniidae represents a group of oribatid mites dwelling exclusively in littoral habitats, as for example rocky shores, boulder beaches or mangrove forests. They show a transoceanic distribution but are restricted to shorelines of warm subtropical and tropical areas (e.g. Schuster 1989; Pfingstl and Schuster 2014).

Tobias Pfingstl

tobias.pfingstl@uni-graz.at

1 Institute of Zoology, University of Graz, Universitaetsplatz 2, 8010 Graz, Austria 
The Eastern Pacific archipelago of Galápagos lies at the equator and offers ideal climatic conditions for these warm-adapted intertidal mites. For that reason, it was not surprising when Schatz (1998) demonstrated that two fortuyniid species have successfully colonized the coasts of this famous group of islands. These two species were recently described as Alismobates galapagoensis Pfingstl and Schatz and Litoribates caelestis Pfingstl and Schatz, and the latter even represented a new genus. Both species are supposed to be derived from Central or South American coasts. With records from six islands, A. galapagoensis shows a wider distribution across the archipelago than L. caelestis, which was only collected on two islands (Pfingstl and Schatz 2017). When Schatz (1998) found these mites, he simultaneously investigated the terrestrial oribatid mite fauna of Galápagos and discovered different morphological forms of a single species (e.g. Scheloribates elegans Hammer, Aeroppia adjacens Mahunka) to be present on different islands or in different habitats of a single island, which indicates ongoing speciation processes. In the intertidal A. galapagoensis and L. caelestis, on the other hand, signs of diversification or speciation were overseen at first sight as no distinct morphological differences between populations of different islands could be detected and specific morphotypes were absent (Pfingstl and Schatz 2017). However, differentiation at an early stage of speciation may only be expressed in slight size and shape differences, indiscernible for the bare eye. Minto et al. (1991) already demonstrated, with morphometric means, that the widespread Antarctic littoral mite Halozetes belgicae (Michael) shows morphological variations between the Antarctic Peninsula and the South Orkney Islands and suggested these geographic variants to be subspecies. A similar but less pronounced situation is given in the assumedly parthenogenetic Fortuynia hawaiiensis Pfingstl and JagersbacherBaumann from the archipelago of Hawaii. Pfingstl and Jagersbacher-Baumann (2016) analysed different populations morphometrically and could demonstrate slight morphological divergence among four islands.

Given the range of research on interisland variability and speciation in Galápagos (e.g. Finston and Peck 1995; Sequeira et al. 2000; Torres-Carvajal et al. 2014), we hypothesized that A. galapagoensis and L. caelestis populations show some kind of diversification among the islands of the archipelago though not detected during the first morphological investigation. Therefore, we performed a comprehensive morphometric analysis of several populations from different islands, first, to confirm our hypothesis of ongoing speciation, second, to assess the degree of variation among the islands and third, to infer evolutionary patterns.

\section{Materials and methods}

All analysed A. galapagoensis specimens were collected by Heinrich Schatz during four extended expeditions to the Galápagos archipelago between 1982 and 1988 (Schatz 1998) and GAL numbers in parenthesis refer to his collection numbers. In order to get a better estimate of intraspecific variation versus interspecific variation, the assumed closely related Alismobates inexpectatus Pfingstl and Schuster was included as outgroup. These specimens were collected on Bermuda by Tobias Pfingstl in 2011 and 2012.

\section{Investigated populations (Fig. 1)}

Alismobates galapagoensis-(1) Bartolomé Island, mangroves near Pinnacle Rock (GAL 85-138); littoral zone; leaf litter, sand, mud and moss under Maytenus octogona, Batis 


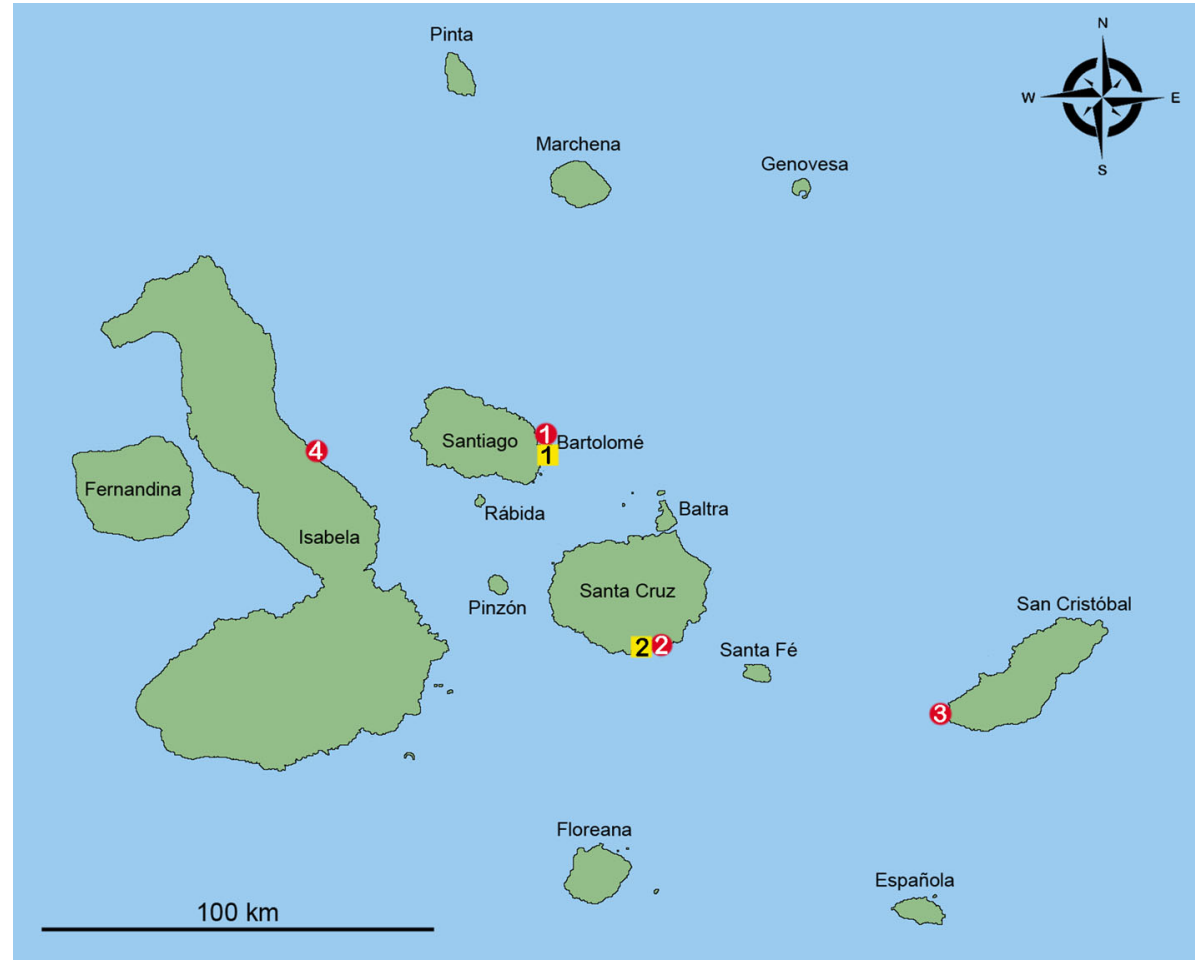

Fig. 1 Map of the Galápagos archipelago showing the sample locations of measured Alismobates galapagoensis (circles) and Litoribates caelestis (square) populations. Numbers refer to location numbers given in text

maritima and Sesuvium edmonstonei; 12.02.1985; $\mathrm{n}=20(5+15 \hat{\jmath})$. (2) Santa Cruz Island, Divine's Bay (GAL 87-431, GAL 87-432); littoral zone; algae from rocks and mangrove roots (Rhizophora mangle); 29.12.1986; $\mathrm{n}=4$ (3, 1今ึ). (3) San Cristóbal Island, south of wreck Bay (GAL 87-476); littoral zone; decayed leaf litter from Sesuvium portulacastrum, Avicennia germinans and Laguncularia racemosa; 04.01.1987; $\mathrm{n}=14$ (7우, 7§). (4) Isabela island, Punta García, north of vulcan Alcedo (GAL 87-702); arid zone; leaf litter and soil under Bursera graveolens, Cordia lutea and C. leucophlyctis; 21.02.1987; $\mathrm{n}=20$ (8ㅇ, 12\}).

Alismobates inexpectatus-Bermuda, Tobacco Bay; littoral zone; algae (Bostrychia tenella) from rocks; 12.04.2012; $\mathrm{n}=20(10$ 우 $10 \hat{\jmath})$.

Litoribates caelestis-(1) Bartolomé Island, mangroves near Pinnacle Rock (GAL 85-137, GAL 87-424); littoral zone; leaf litter, sand, mud and moss under Maytenus octogona; 12.02.1985 and 26.12.1986; $\mathrm{n}=5$ (2ㅇ, 3今). (2) Santa Cruz Island, Puerto Ayora, near 'Fragata' (GAL 87-434); littoral zone; leaf litter and soil under Rhizophora mangle; 30.12.1986; $\mathrm{n}=15(7$ ㅇ, 8今).

\section{Measurements and variables}

Specimens were embedded in lactic acid for temporary slides and measurements were performed using a compound light microscope (Olympus) and ocular micrometre. Sixteen continuous variables were measured in Alismobates and 15 in Litoribates (Fig. 2). 

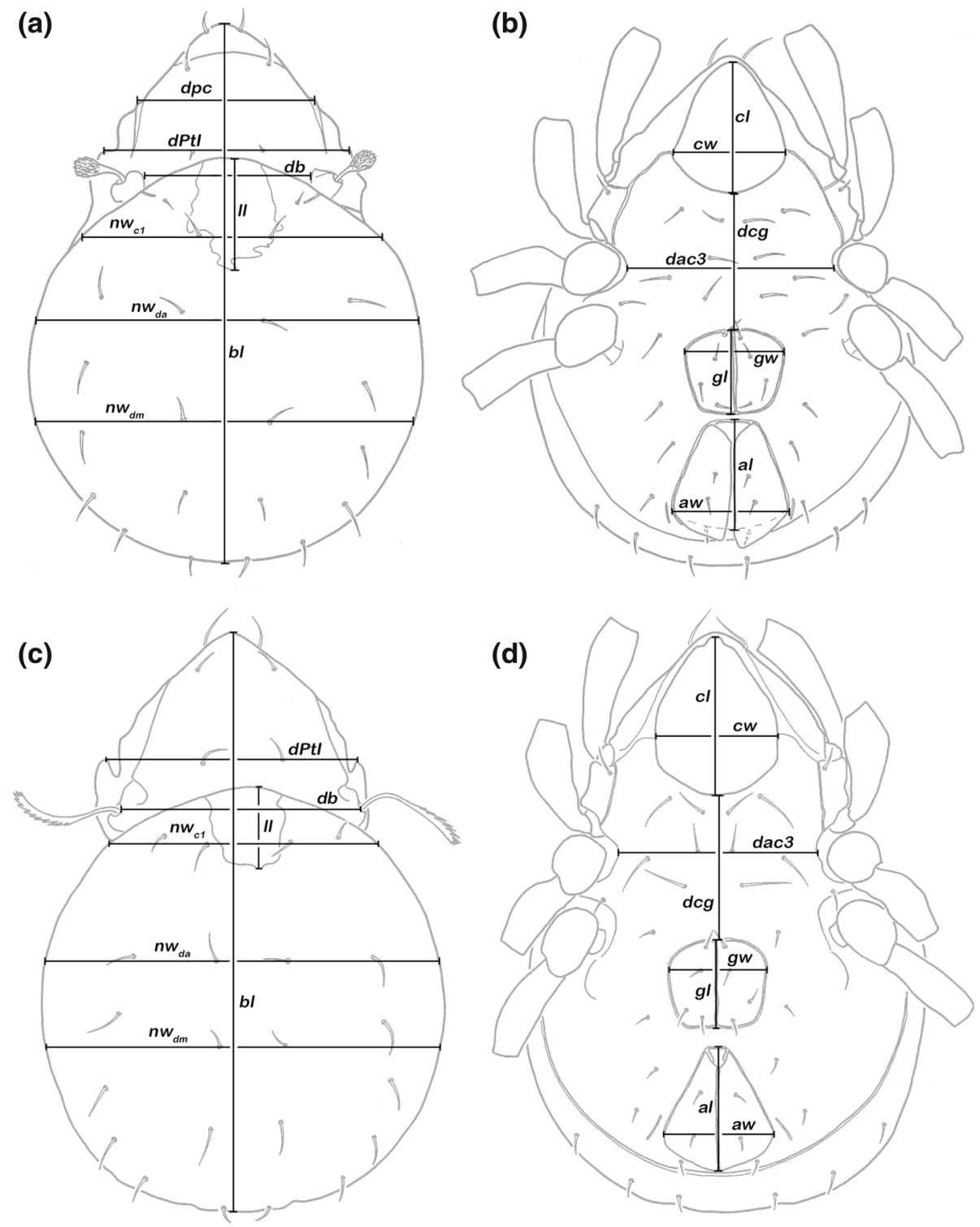

Fig. 2 Graphic illustration of measured continuous variables shown on simplified drawings of Alismobates galapagoensis (a, b) and Litoribates caelestis (c, d). Dorsal aspect: bl-body length, dPtI-distance between pedotecta I, $d p c$-distance between prodorsal carinae, $d b$-distance between bothridia, $l l$ lenticulus length, $n w_{c 1}$-notogastral width on level of seta $c_{1}, n w_{d a}$-notogastral width on level of seta $d a$, $n w_{d m}$-notogastral width on level of seta $d m$. Ventral aspect: $c l$-camerostome length, $c w-c a m e r o s t o m e$ width, $d c g$ - distance between camerostome and genital orifice, dac3-distance between acetabula 3, glgenital orifice length, $g w$ - genital orifice width, al — anal opening length, $a w$ —anal opening width 


\section{Statistical analysis}

For univariate statistics, only five randomly chosen specimens out of the 15 available males of A. galapagoensis from Bartolomé were used so that each population consisted of an almost equal number of males and females. In all other populations (A. inexpectatus from Bermuda, A. galapagoensis from Santa Cruz, San Cristóbal and Isabela), all available specimens were used. Mean, minimum, maximum, standard deviation and coefficient of variation (cv) were calculated, and Kruskal-Wallis and Mann-Whitney U test were used for comparing the means of variables between all groups and for pairwise comparisons, respectively.

Multivariate analyses of all specimens listed above were performed on $\log _{10}$-transformed raw and size-corrected data. Size correction was done by dividing each variable through the geometric mean of the respective specimen (e.g. Jagersbacher-Baumann 2014; Pfingstl and Jagersbacher-Baumann 2016). In our case, the geometric mean was calculated as the 16th root of the product of all 16 variables measured for each specimen in Alismobates and as the 15th root of the product of all 15 variables in Litoribates. To reveal patterns of morphological variation, Principal Components Analyses (PCA) were conducted, and to determine the most important variables for differentiating the groups, Canonical Variates Analysis (CVA) was performed in Alismobates and Discriminant Analysis (DA) in Litoribates.

Preliminary multivariate analyses revealed a size-dependent sexual dimorphism with larger females in all investigated populations. As this sexual dimorphism resulted in overlapping areas in the graphs, males and females of Alismobates were analysed separately in PCA and CVA for clarification. The performance of the classification by CVA/ DA was tested by calculating the number of specimens correctly classified by all-samples CVA/DA and leave-one-out cross-validation CVA/DA. Multivariate Analysis of Variance (MANOVA) was used for testing the equality of means of all populations of Alismobates. To determine phenetic similarities, unrooted neighbour-joining (NJ) trees were constructed using the squared Mahalanobis distances between the populations gained by discriminant analyses based on raw and size-corrected data (Kerschbaumer et al. 2011; JagersbacherBaumann 2015). For testing equality of means and for constructing the NJ-trees, males and females were again pooled together. All analyses were performed with PAST 3.11 (Hammer et al. 2001).

\section{Results}

\section{Alismobates populations}

\section{Descriptive/univariate statistics}

Univariate analyses of A. inexpectatus from Bermuda and A. galapagoensis from Bartolomé, Santa Cruz, San Cristóbal and Isabela revealed significant differences in all variables between all five populations (Kruskal-Wallis test: $p<0.01$ ) (Table 1). Pairwise comparisons of populations by Mann-Whitney U test showed that most differences existed between A. galapagoensis populations from San Cristóbal versus Bartolomé and from San Cristóbal versus Isabela, and between A. inexpectatus (from Bermuda) versus A. galapagoensis from Bartolomé as well as between $A$. inexpectatus (Bermuda) versus $A$. 


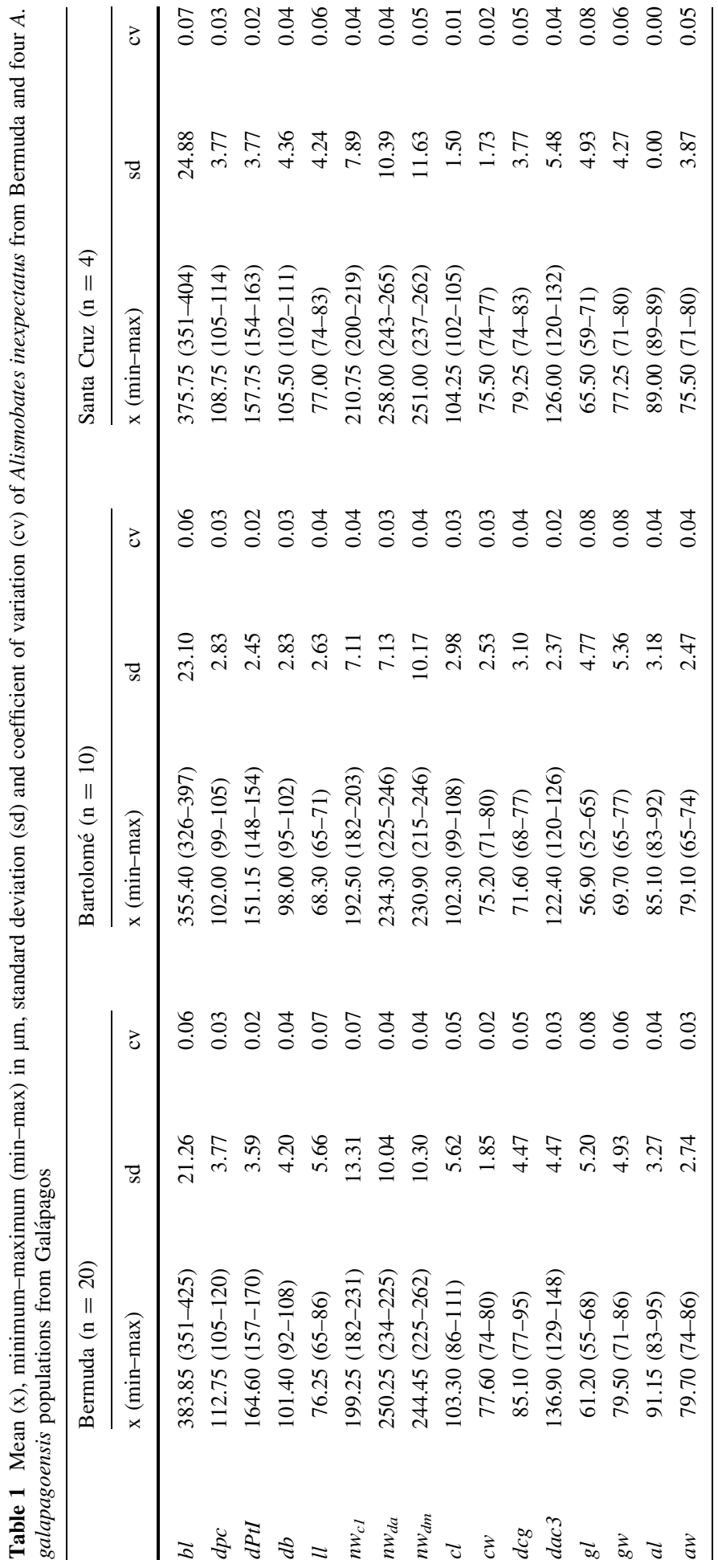




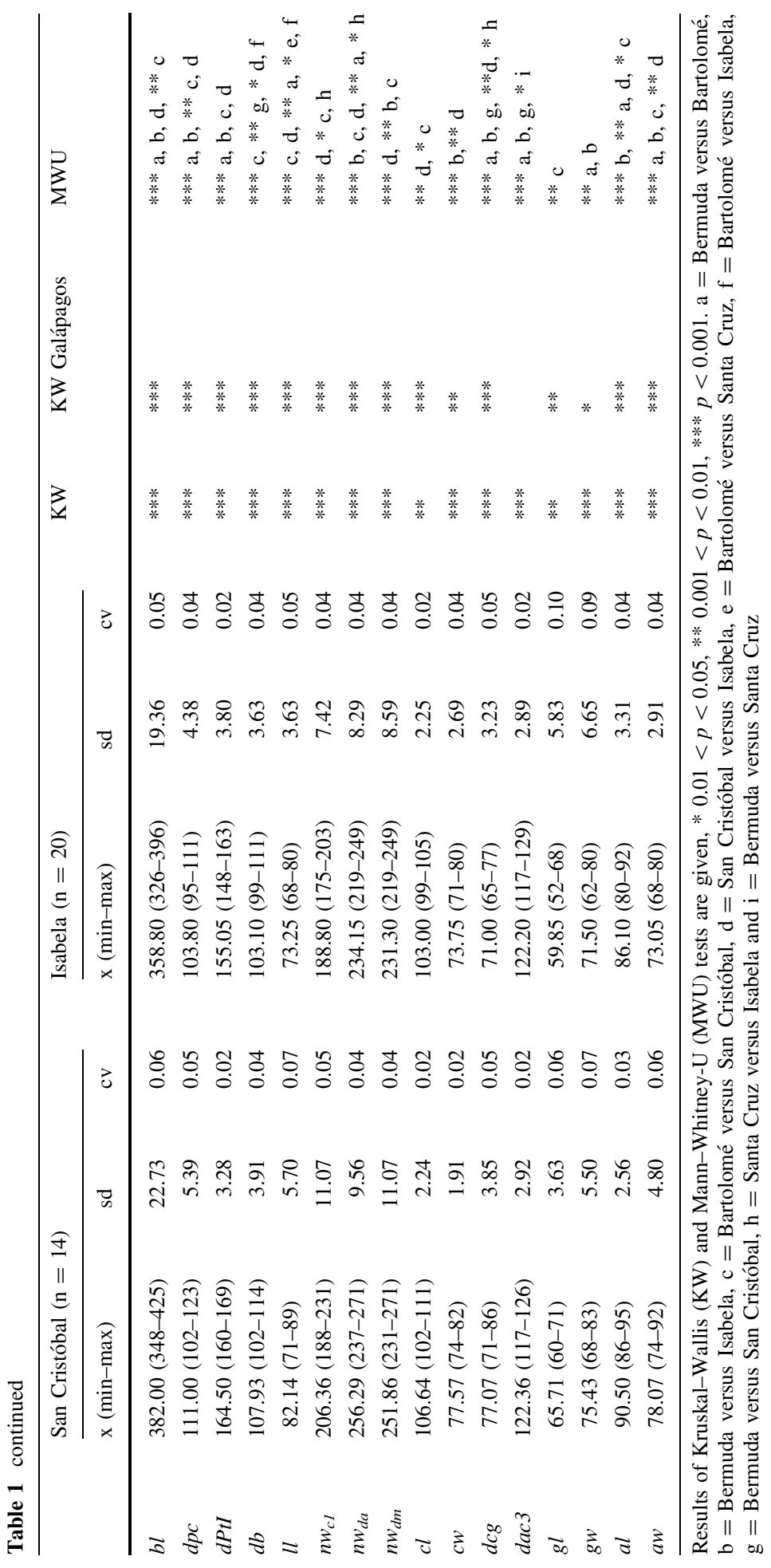


galapagoensis from Isabela. Among all analysed populations, A. inexpectatus was by trend largest as it had the highest values for most of the measured variables. When A. inexpectatus was removed from the analysis, Kruskal-Wallis still revealed significant differences $(p<0.05)$ between the remaining populations from Galápagos in all variables except dac3. Within the A. galapagoensis populations, the specimens from San Cristóbal were largest and those from Bartolomé were smallest. The variability of characters as indicated by $\mathrm{cv}$ was moderate with a maximum cv value of 0.10 in all populations. In all populations, highest $\mathrm{cv}$ values (between 0.07 and 0.10 ) were calculated for either $g l, g w$ or both, and both these variables are directly related to gender.

\section{Multivariate analyses}

PCA on log-transformed raw data resulted in a separation of the analysed populations in females as well as in males, but in males there were more overlapping areas than in females (Fig. 3a). The best separation was given by a combination of PC1 and PC2, which together

(a)

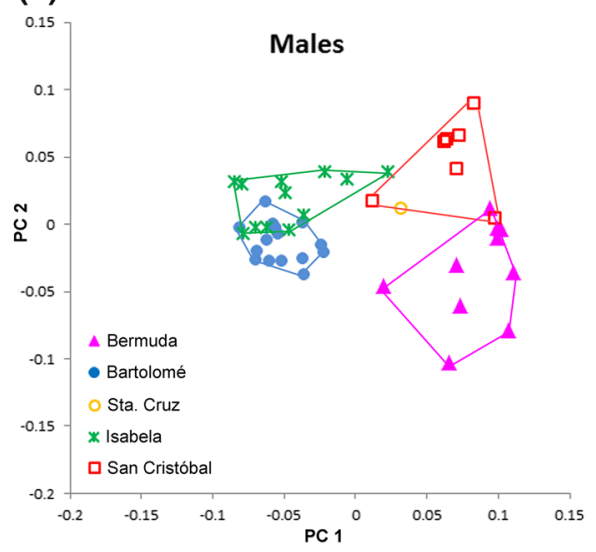

(b)

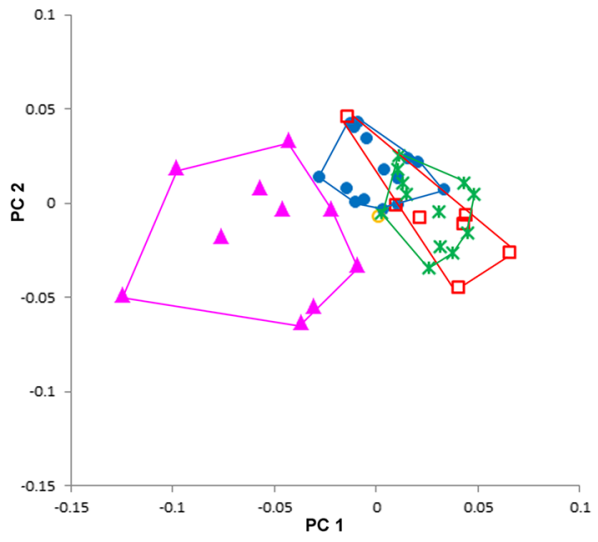

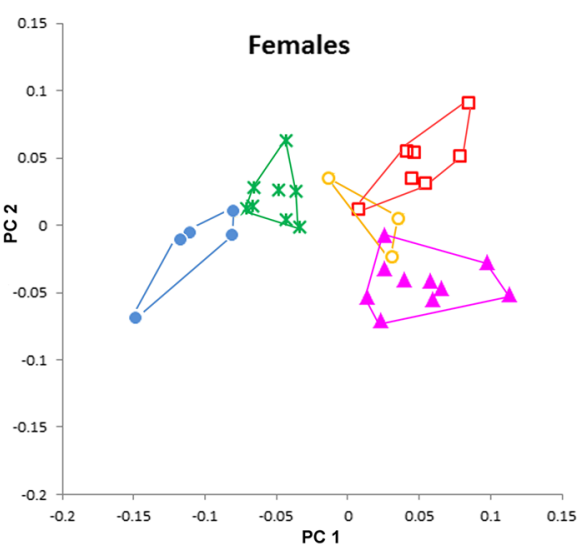

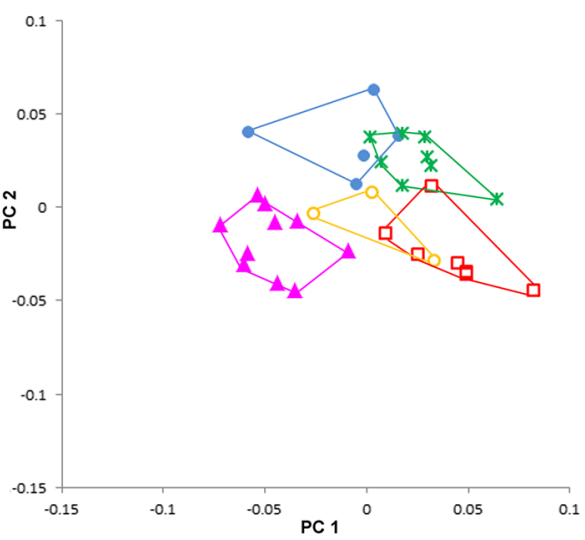

Fig. 3 Scatter plots gained from PCA on $\log _{10}$-transformed a raw data and $\mathbf{b}$ size-corrected data of Alismobates inexpectatus from Bermuda (a different species) and four A. galapagoensis populations from Galápagos 
explained $72.69 \%$ of the total variation in males (PC1 55.60\%, $\mathrm{PC} 217.09 \%$ ) and $70.50 \%$ in females (PC1 51.71\%, PC2 18.79\%). In both cases, all variables on PC1 had positive loadings, a fact that already hints to a correlation between $\mathrm{PC} 1$ and size. A strong correlation was proven when the PC1 values of each specimen were plotted against the respective geometric means ( $\mathrm{r}=0.99$ in both males and females). In accordance with the results from the univariate statistic, A. inexpectatus from Bermuda and A. galapagoensis populations from San Cristóbal and Santa Cruz were populations with larger individuals whereas A. galapagoensis populations from Isabela and Bartolomé consisted of smaller specimens. Females from Isabela and Bartolomé were separated from each other on PC1 whereas males of the respective populations overlapped. In males as well as in females, PC2 at least partly separated the A. galapagoensis populations from Isabela and San Cristóbal from the population from Bartolomé and from A. inexpectatus. The variables with highest loadings were $d c g$ for males and $l l$ for females on PC1 and $l l$ and $d c g$ for males and $d c g$, dac3 and $l l$ for females on PC2.

After size correction, the A. galapagoensis males of all populations from Galápagos clustered together, but there was still a separation, albeit with overlaps, between the females (Fig. 3b). The decrease of total variation after size correction was $49.93 \%$ in males and $44.69 \%$ in females. Males as well as females of $A$. inexpectatus were separated from the A. galapagoensis populations by a combination of $\mathrm{PC} 1$ and $\mathrm{PC} 2$, and the males of $A$. inexpectatus showed a remarkable variability on both axes. In males, PC1 and PC2 together explained 54.49\% of the total variation (PC1 37.74\%, PC2 16.76\%), and variables with highest loadings were $d c g$ on PC1 and $l l$ on PC2. In females, PC1 and PC2 together explained $51.96 \%$ of the total variation (PC1 34.18\%, PC2 17.79\%). In A. galapagoensis populations, PC1 separated the population from Bartolomé and Santa Cruz from those from San Cristóbal and Isabela, and PC2 separated the populations from San Cristóbal and Santa Cruz from those from Isabela and Bartolomé. The variables $d c g$ and dac3 were the ones with the highest loadings on PC1, and $l l$ on PC2.

In males, CVA on both, log-transformed raw and size-corrected data, revealed a partial separation of the populations: Alismobates inexpectatus and A. galapagoensis from San Cristóbal were always well separated from each other and from the remaining A. galapagoensis populations, which clustered together (Fig. 4). In CVA on raw data, CV1 explained $59.16 \%$ of the total variation and CV2 explained $31.64 \%$. Classification by CVA revealed that $97.78 \%$ of all specimens could be correctly classified in all-samples CVA and $80.00 \%$ in leave-one-out cross-validated (LOO-CV) CVA. Misclassified specimens almost exclusively belonged to the A. galapagoensis populations from Santa Cruz, Isabela and Bartolomé. Alismobates inexpectatus was separated from the other populations on CV1, and the variables contributing most to variation on this axis were $d c g, d a c 3$ and $g w$. CV2 separated A. galapagoensis from San Cristóbal from the other populations, and variables with high loadings on this axis were $l l$ and $g l$ (Table 2). After size correction, CV1 explained $69.73 \%$ and CV2 $17.65 \%$ of the total variation, and the power of classification by CVA slightly weakened: the percentage of correctly classified specimens was $97.78 \%$ in all-samples CVA and still $75.56 \%$ in LOO-CV CVA. Again, misclassified specimens mostly belonged to the populations from Santa Cruz and Bartolomé. CV1 separated $A$. inexpectatus and A. galapagoensis from San Cristóbal from each other as well as from the remaining populations, and the variable with the highest loading on this axis was dac3. On $\mathrm{CV} 2$, A. galapagoensis from Bartolomé was separated from the other populations, with an overlap with the population from Isabela. Variables contributing most to variation on CV2 were $l l, c l$ and $c w$. MANOVA revealed highly significant $(p<0.001)$ differences between all populations in raw data as well as in size-corrected data. 
(a)
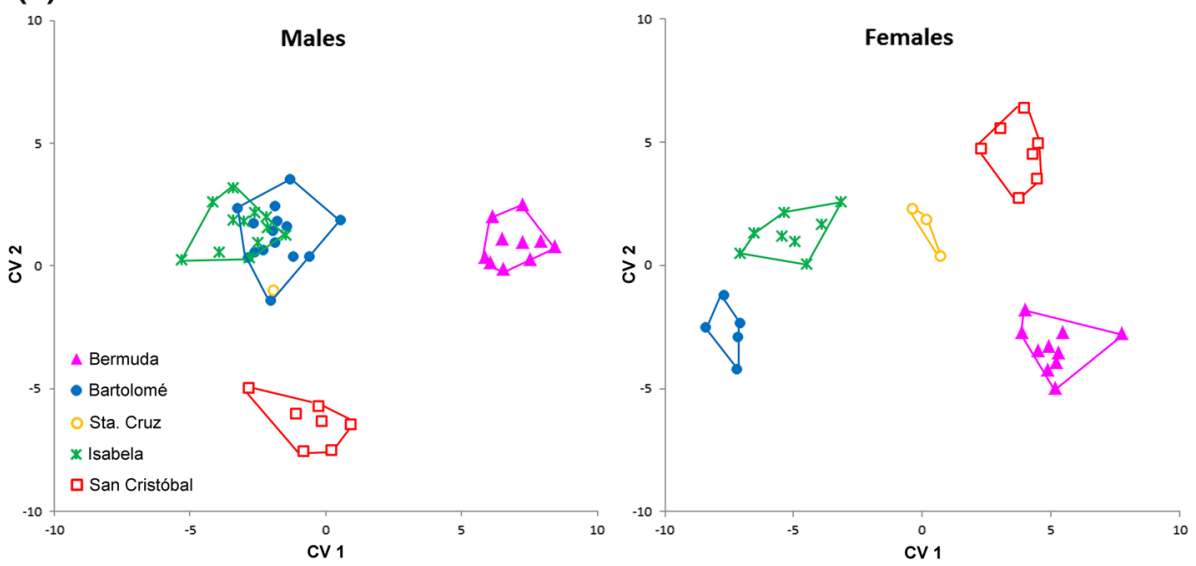

(b)
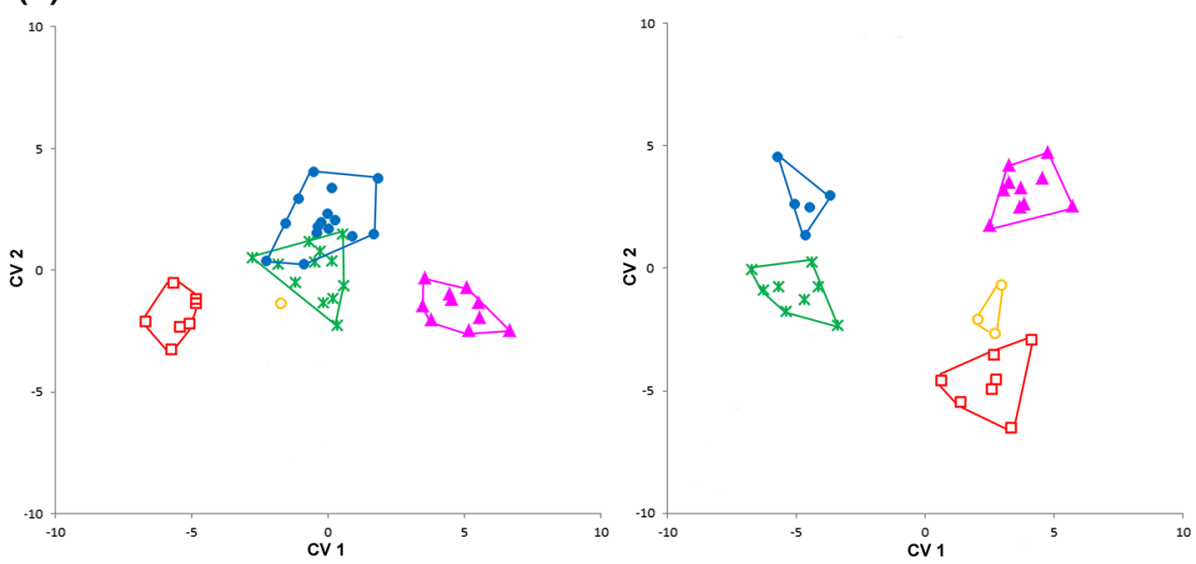

Fig. 4 Scatter plots gained from CVA on $\log _{10}$-transformed a raw data and b size-corrected data of Alismobates inexpectatus from Bermuda (a different species) and four A. galapagoensis populations from Galapagos

CVA on both log-transformed raw and size-corrected data of females resulted in a separation of all populations (Fig. 4). In CVA on raw data, CV1 explained $64.37 \%$ and CV2 explained $23.76 \%$ of the total variation. On CV1, the A. galapagoensis populations from Isabela and Bartolomé were separated from the population from Santa Cruz and also from the population from San Cristóbal and A. inexpectatus. CV2 showed a separation between $A$. galapagoensis from Isabela, Santa Cruz and San Cristóbal from A. galapagoensis from Bartolomé and A. inexpectatus. Variables contributing most to variation on the respective axes were $l l$ and $d c g$ on CV1 and $l l, d c g$ and $d a c 3$ on CV2 (Table 2). In all-samples CVA, $100 \%$ of all specimens could be classified correctly, and in LOO-CV CVA this number dropped to $87.88 \%$. After size correction, CV1 explained $56.75 \%$ and CV2 $33.62 \%$ of the total variation. CV1 separated A. galapagoensis from Isabela and Bartolomé from the remaining populations, and CV2 separated A. inexpectatus from all A. galapagoensis populations, except for Bartolomé. Variables with high loadings were $d c g$ on CV1 and $l l, d c g$ and $d a c 3$ on CV2 (Table 2). The percentage of correctly classified specimens dropped to $90.91 \%$ in all- 
Table 2 Loadings of the two canonical axes CV1 and CV2 for CVA on one population of Alismobates inexpectatus from Bermuda and four populations of A. galapagoensis from Galápagos

\begin{tabular}{|c|c|c|c|c|c|c|c|c|}
\hline & \multicolumn{4}{|l|}{ Males } & \multicolumn{4}{|c|}{ Females } \\
\hline & \multicolumn{2}{|c|}{ Raw data } & \multicolumn{2}{|c|}{ Size-corrected data } & \multicolumn{2}{|c|}{ Raw data } & \multicolumn{2}{|c|}{ Size-corrected data } \\
\hline & CV1 & CV2 & CV1 & CV2 & CV1 & CV2 & CV1 & CV2 \\
\hline$b l$ & 0.003 & -0.003 & 0.000 & 0.000 & 0.002 & 0.000 & -0.001 & 0.000 \\
\hline$d p c$ & 0.003 & -0.002 & 0.001 & 0.001 & 0.004 & 0.000 & 0.001 & 0.000 \\
\hline$d P t I$ & 0.003 & -0.003 & 0.000 & -0.001 & 0.003 & 0.000 & 0.000 & 0.000 \\
\hline$d b$ & 0.000 & -0.004 & -0.003 & 0.002 & 0.001 & 0.004 & -0.003 & -0.003 \\
\hline$l l$ & 0.002 & -0.006 & -0.003 & -0.005 & 0.005 & 0.005 & 0.002 & -0.005 \\
\hline$n w_{c 1}$ & 0.001 & -0.003 & -0.002 & 0.004 & 0.003 & 0.002 & 0.001 & -0.001 \\
\hline$n w_{d a}$ & 0.002 & -0.004 & -0.001 & 0.000 & 0.003 & 0.002 & 0.001 & -0.001 \\
\hline$n w_{d m}$ & 0.003 & -0.004 & 0.000 & -0.001 & 0.002 & 0.003 & -0.001 & -0.002 \\
\hline$c l$ & 0.000 & -0.002 & -0.002 & 0.005 & 0.000 & 0.002 & -0.003 & -0.001 \\
\hline$c w$ & 0.002 & -0.002 & 0.000 & 0.005 & 0.001 & 0.000 & -0.002 & 0.001 \\
\hline$d c g$ & 0.008 & -0.002 & 0.004 & -0.003 & 0.005 & -0.005 & 0.004 & 0.005 \\
\hline dac3 & 0.005 & 0.001 & 0.005 & 0.002 & 0.003 & -0.005 & 0.000 & 0.006 \\
\hline$g l$ & 0.001 & $-\mathbf{0 . 0 0 7}$ & -0.004 & -0.002 & 0.002 & 0.004 & -0.001 & -0.003 \\
\hline$g w$ & 0.006 & -0.002 & 0.003 & -0.003 & 0.003 & -0.001 & 0.000 & 0.001 \\
\hline al & 0.003 & -0.003 & 0.000 & 0.001 & 0.002 & 0.000 & -0.001 & 0.001 \\
\hline$a w$ & 0.004 & -0.003 & 0.001 & -0.004 & 0.004 & 0.001 & 0.002 & 0.000 \\
\hline
\end{tabular}

High loadings explaining differences between the groups are given in bold

samples CVA and 78.79\% in LOO-CV CVA. Misclassified specimens were found mostly in A. inexpectatus and A. galapagoensis from Isabela. MANOVA revealed highly significant $(p<0.001)$ differences between all populations in raw data as well as in size-corrected data.

The unrooted NJ trees based on phenetic similarities revealed that raw data showed a better separation between populations than size-corrected data (Fig. 5). In the tree based on raw data, A. inexpectatus was clearly separated from all A. galapagoensis populations. Within A. galapagoensis, the populations from Isabela and Bartolomé were closest together, and the population from San Cristóbal was most different from the remaining populations (Fig. 5a). A very similar pattern was still recognizable in size-corrected data, but the distances between each population are larger (Fig. 5b).

\section{Litoribates populations}

\section{Descriptive/univariate statistics}

There are few significant differences between the two populations from Bartolomé and Santa Cruz (Table 3), only the two variables describing the camerostome $c l$ and $c w$ differ significantly $(p<0.05)$.

\section{Multivariate analyses}

PCA on log-transformed raw data resulted in a partial separation of the two populations (Fig. 6a). The combination of PC1 and PC2 explained $69.82 \%$ of the total variation (PC1 
(a)

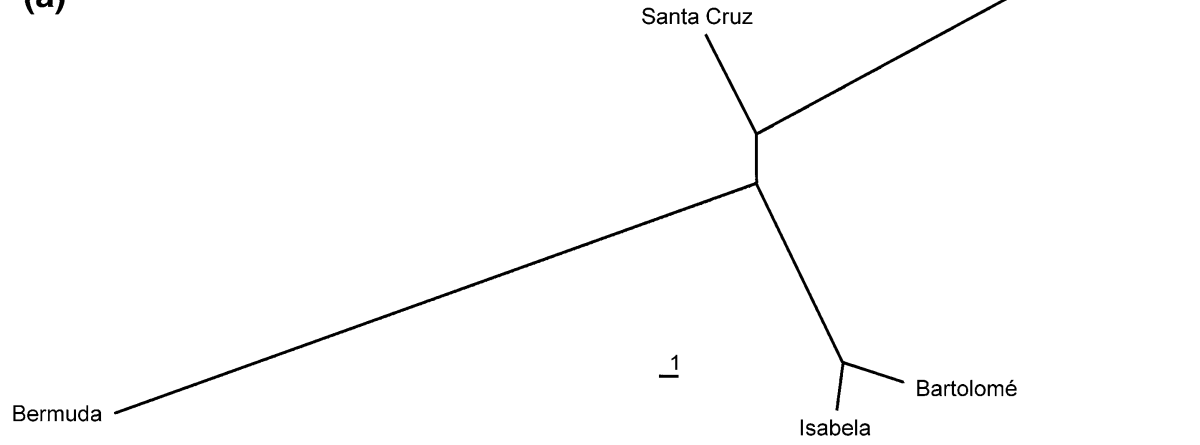

(b)

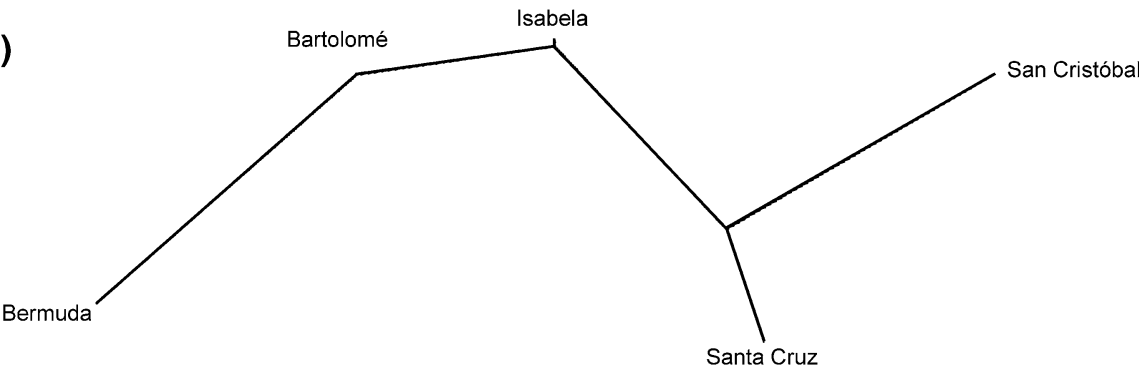

Fig. 5 Unrooted neighbour-joining (NJ) trees of Alismobates inexpectatus from Bermuda and four A. galapagoensis populations from Galapagos based on squared Mahalanobis distances obtained from canonical variates analysis (CVA) on canonical variates values of $\log _{10}$-transformed a raw data and $\mathbf{b}$ size-corrected data

Table 3 Mean (x), minimum-maximum (min-max) in $\mu \mathrm{m}$, standard deviation (sd) and coefficient of variation (cv) of two Litoribates caelestis populations from Galápagos

\begin{tabular}{|c|c|c|c|c|c|c|c|}
\hline & \multicolumn{3}{|l|}{ Bartolomé $(\mathrm{n}=5)$} & \multicolumn{3}{|c|}{ Santa Cruz $(\mathrm{n}=15)$} & \multirow[t]{2}{*}{ MWU } \\
\hline & $\mathrm{x}(\min -\max )$ & $\mathrm{sd}$ & $\mathrm{cv}$ & $\mathrm{x}(\min -\max )$ & sd & $\mathrm{cv}$ & \\
\hline$b l$ & $324.20(307-342)$ & 13.31 & 0.04 & $320.93(308-336)$ & 8.97 & 0.03 & \\
\hline$d P t I$ & $145.00(142-148)$ & 3.00 & 0.02 & $142.60(139-148)$ & 2.59 & 0.02 & \\
\hline$d b$ & $129.60(126-135)$ & 3.29 & 0.03 & $128.80(126-132)$ & 2.40 & 0.02 & \\
\hline$l l$ & $48.40(46-52)$ & 3.29 & 0.07 & $50.60(43-55)$ & 2.97 & 0.06 & \\
\hline$n w_{c 1}$ & $150.40(145-160)$ & 6.50 & 0.04 & $154.33(132-172)$ & 9.77 & 0.06 & \\
\hline$n w_{d a}$ & 200.60 (191-212) & 7.77 & 0.04 & 204.20 (194-214) & 6.41 & 0.03 & \\
\hline$n w_{d m}$ & $199.40(188-212)$ & 9.10 & 0.05 & $201.80(191-215)$ & 5.98 & 0.03 & \\
\hline$c l$ & $90.80(80-95)$ & 6.22 & 0.07 & 96.00 (89-99) & 3.00 & 0.03 & $*$ \\
\hline$c w$ & $69.80(65-71)$ & 2.68 & 0.04 & $67.27(65-69)$ & 1.44 & 0.02 & $*$ \\
\hline$d c g$ & $80.60(71-92)$ & 7.77 & 0.10 & $73.53(66-80)$ & 3.60 & 0.05 & \\
\hline$d a c 3$ & $108.60(105-114)$ & 3.91 & 0.04 & $110.07(108-112)$ & 1.53 & 0.01 & \\
\hline$g l$ & $47.20(43-49)$ & 2.68 & 0.06 & $44.93(40-49)$ & 3.06 & 0.07 & \\
\hline$g w$ & $54.00(49-59)$ & 3.74 & 0.07 & $54.07(49-62)$ & 4.56 & 0.08 & \\
\hline$a l$ & $70.00(66-74)$ & 3.08 & 0.04 & $69.00(65-71)$ & 1.85 & 0.03 & \\
\hline$a w$ & $53.80(52-55)$ & 1.64 & 0.03 & $55.13(52-59)$ & 2.29 & 0.04 & \\
\hline
\end{tabular}

Results of Mann-Whitney-U (MWU) test are given, ${ }^{*} p<0.05$ 
(a)

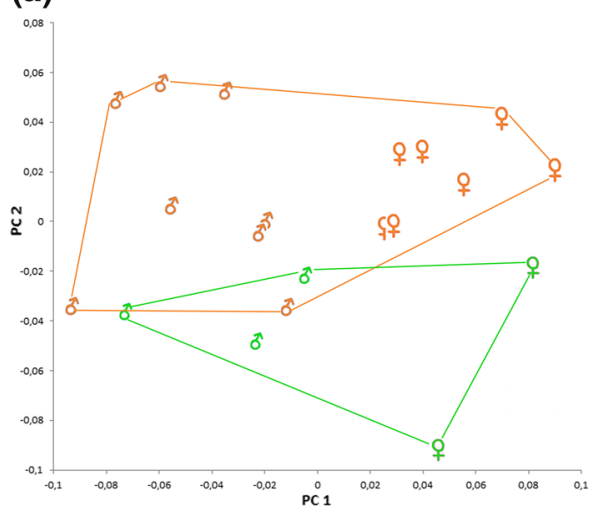

(b)

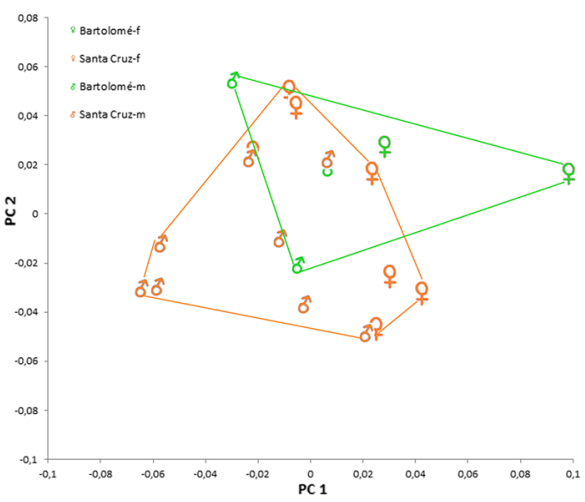

Fig. 6 Scatter plots gained from PCA on $\log _{10}$-transformed a raw data and $\mathbf{b}$ size-corrected data of Litoribates caelestis populations from Bartolomé and Santa Cruz

47.30\%, PC2 22.52\%). PC1 was strongly correlated with size defined as the geometric mean $(r=0.99)$ and there was a clear variation present on this component. Thus, all specimens with high PC1 values were large individuals, and all of them were females. There was a clear separation between males and females along PC1, indicating a sexual dimorphism connected with overall size. The two populations were separated mainly from each other on PC2. Variables contributing most to variation on this component and thus to the separation between the populations were $l l$ and $d c g$. The separation between males and females on PC1 was clearer than the separation between the two populations on PC2. After size correction, which resulted in a reduction of $32.88 \%$ of the total variation, the two populations as well as the two sexes overlapped in PCA (Fig. 6b).

Discriminant analyses (DA) divided the two populations into two groups in both raw and size-corrected data. Variables with highest loadings, thus mainly responsible for separation of the two groups, were $d c g$ in raw data and $d c g, c l$ and $g w$ in size-corrected data. However, the groups did not significantly differ from each other as Bonferroni corrected Hotelling's $\mathrm{T}^{2}$ tests revealed no significant differences $(p=0.15$ in raw data and $p=0.67$ in size-corrected data). Accordingly, a jack-knifed discriminant analysis was only able to classify 65 and $60 \%$ of the specimens correctly in raw data and size-corrected data, respectively.

\section{Discussion}

\section{General aspects}

Describing A. galapagoensis, Pfingstl and Schatz (2017) already noticed a conspicuous morphological similarity to the Bermudian $A$. inexpectatus, suggested a close relationship of the two species and further stated that A. galapagoensis may be derived from Central or South American shores. In the meantime, Alismobates specimens strongly resembling $A$. inexpectatus were found on the Caribbean coast of Panama (Pfingstl, unpublished data). Whether these specimens belong to A. inexpectatus or do represent another sister species of A. galapagoensis cannot be answered yet and will be part of future investigations. 
However, this record clearly fills the large geographic gap between Galápagos and Bermuda and supports the idea that A. galapagoensis may have a Central American origin (Pfingstl and Schatz 2017). Several studies propose that colonization of Galápagos by different organisms happened via passive drift on the Humboldt Current, which transports cool waters from the South American coast to the archipelago (e.g. Sequeira et al. 2000; Caccone et al. 2002; Torres-Carvajal et al. 2014). Considering their presently known distribution, we presume that the investigated mites probably reached Galápagos via the Panamá Current, which carries warm tropical waters from Central America (Lea et al. 2006) and fuses with the Peru Coastal Current before arriving at Galápagos.

Despite the similarity between $A$. inexpectatus and A. galapagoensis, the present morphometric analysis clearly separates both species and hence confirms their distinctness. The present study also revealed the presence of a slight sexual dimorphism concerning body size in all investigated species. Females are by trend larger and possess a relatively larger genital opening than males. This is not unusual as a small degree of sexual dimorphism is common among most oribatid mites with females being slightly larger and showing larger genital plates than males; only $1 \%$ of all species show explicit differences between the genders (e.g. Behan-Pelletier 2015). However, a rather unusual result of the present study is that females of A. galapagoensis from different islands show higher variation in shape than the respective males. As can be seen in Fig. 3b, females from different populations are clearly separated from each other, whereas the according males cluster. The reason for this sex related difference in shape variation is presently unknown and remains puzzling.

\section{Variation among islands}

The two Litoribates populations from Bartolomé and Santa Cruz did not show significant differences in their variables neither in univariate nor in multivariate analysis, although a slight separating trend can be observed in the PCA graphs. Bartolomé and Santa Cruz lie only approx. $30 \mathrm{~km}$ apart and both populations were found in similar mangrove leaf litter habitats, accordingly the present result is not surprising.

The Alismobates populations from four different islands of the Galápagos archipelago, on the other hand, showed significant differences in all univariate and multivariate analyses. Although size-correction decreased the total variation, the populations could still be separated from each other (at least in females), which strongly points to genetically induced variation (e.g. Stekolnikov and Klimov 2010). In the raw data, size differences with individuals from San Cristóbal being the largest and specimens from Bartolomé and Isabela being the smallest were evident. Pfingstl and Jagersbacher-Baumann (2016) demonstrated similar variations among Hawaiian $F$. hawaiiensis populations, whereas they could not explain if these divergences represented cases of phenotypic plasticity or cases of diverging genomes. In the present case an assessment is also difficult to make because our knowledge about ecological factors in the microhabitat and their influence on phenotypic plasticity in these mites is limited. Nevertheless, the size variation of the Galápagos Alismobates populations shows a clear gradient from East (large) to West (small) which rather points to directional diverging genomes than to non-genetic intraspecific variation.

Apart from the overall size differences, the Alismobates populations also show several significant differences in single variables. The mainly affected variables are the lenticulus length, the distance between camerostome and genital orifice and the distance between acetabula III. The latter two variables are properties of the epimeral area which indicates 


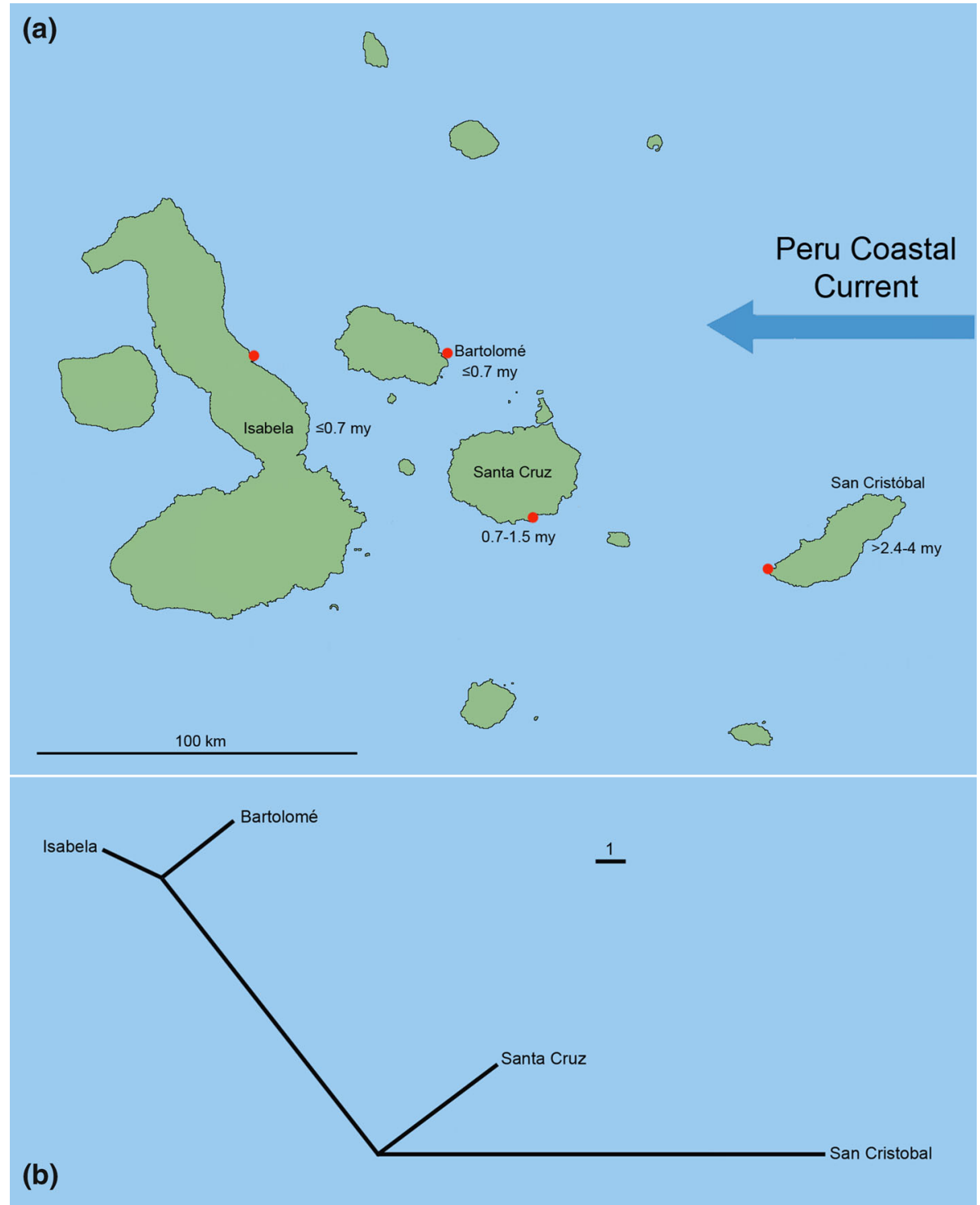

Fig. 7 Biogeographical aspects of Alismobates galapagoensis populations. a Map of the Galápagos archipelago showing approximate geological ages of the islands (after Simkin 1984) and location of investigated populations. b Spatially modified unrooted NJ-tree based on squared Mahalanobis distances obtained from canonical variates analysis (CVA) (raw data) reflecting similarities between geography and morphological differentiation

that this whole region is subject to strong variation. Why these traits vary between the island populations is unknown and could only be speculated at this point in time.

Another interesting result of the present morphometric study is that the morphological divergence between the various Alismobates populations seems to correlate with the geographic distance between the islands (compare Fig. 7). The larger the distance between the islands, the larger are the morphological differences between the respective 
populations. Considering gene flow between islands, this would mean genetic exchange has happened less frequently between populations of distant islands than between closer located islands. This result together with the clear gradient in size indicates that colonization of the islands might have happened only in one direction, from East to West. A similar colonization route has also been proposed for other flightless animals, for example weevils (Sequeira et al. 2000), geckos (Torres-Carvajal et al. 2014) or giant tortoises (Caccone et al. 2002).

This leads us to the question of how littoral mites can move from one landmass to the other. Schatz (1991) already discussed possible agents for dispersal of mites to remote islands in detail and stated that there are mainly three modes: first, rafting on ocean currents, second, transport by other organisms (mainly birds) and third, introduction by humans. However, birds and ships can travel fast, arbitrarily and in all directions between the islands of the Galápagos archipelago and if mites would mainly be transported by these, gene flow would not be restricted considerably by distance and consequently morphological variance would be more balanced across the archipelago. Ocean currents, on the other hand, are not directly linear and relatively slow moving dispersal agents therefore the chance of surviving this mode of transport clearly decreases with distance. According to this, gene flow between far distant populations happens more seldom and subsequently leads to stronger diverging genomes and morphologies. One still might argue that the same may apply to transport by birds or by wind, but the investigated mites do not show any behavioural or morphological adaptations to phoresy (e.g. Pfingstl 2017) and wind dispersal has mainly been shown in mites associated with tree habitats (e.g. Lehmitz et al. 2011). Pfingstl (2017) already reviewed data on dispersal mechanisms of intertidal oribatid mites and came to the conclusion that hydrochory, i.e. transport along ocean currents, is the most likely mode of long distance transport at least for fortuyniid mites. The observed correlation between geographic distance and morphological divergence may be another indication that these intertidal mites have been predominantly dispersed throughout Galápagos by drifting on ocean currents. Recent prevailing surface currents within the archipelago basically run in a north-westerly direction (Caccone et al. 2002), which would be congruent with the above mentioned theory. Without molecular genetic data it is not yet possible to assess the degree of gene flow between the island populations and to tell how far this diversification has actually proceeded on a genetic base. However, present data clearly show morphological divergence among the different populations which we believe is a result of an ongoing speciation process. Furthermore, we think that the correlation between morphological divergence and geographic distance is mainly a result of hydrochorous dispersal between the islands.

Acknowledgements Open access funding provided by University of Graz. First of all, we would like to thank Drs. Heinrich and Irene Schatz. They performed comprehensive studies on the oribatid mite fauna of the Galápagos Islands over years and we were allowed to investigate part of this invaluable material collected on these occasions. We also want to thank Dr. L. Baert, Dr. J.-P. Maelfait and Dr. K. Desender for contributing mites to this collection. We are also grateful to the Charles Darwin Research Station, the Servicio Parque Nacionál Galápagos and the authorities from Ecuador for the logistic support and collecting permits provided for H. and I. Schatz. This publication is contribution number 2167 of the Charles Darwin Foundation for the Galapagos Islands.

Open Access This article is distributed under the terms of the Creative Commons Attribution 4.0 International License (http://creativecommons.org/licenses/by/4.0/), which permits unrestricted use, distribution, and reproduction in any medium, provided you give appropriate credit to the original author(s) and the source, provide a link to the Creative Commons license, and indicate if changes were made. 


\section{References}

Behan-Pelletier VM (2015) Review of sexual dimorphism in brachypyline oribatid mites. Acarologia 55:127-146

Caccone A, Gentile G, Gibbs JP, Fritts TH, Snell HL, Betts J, Powell JR (2002) Phylogeography and history of Giant Galápagos Tortoises. Evolution 56(10):2052-2066

Finston TL, Peck SB (1995) Population structure and gene flow in Stomion: a species swarm of flightless beetles of the Galápagos Islands. Heredity 15:390-397

Hammer Ø, Harper DAT, Ryan PD (2001) PAST: paleontological statistics software package for education and data analysis. Palaeontol Electron 4:1-9

Jagersbacher-Baumann J (2014) Species differentiation of scutacarid mites (Heterostigmatina) using multivariate morphometric methods. Exp Appl Acarol 62:279-292. doi:10.1007/s10493-013-9747-X

Jagersbacher-Baumann J (2015) Traditional and geometric morphometric analyses reveal homogeneity in European Scutacarus acarorum Goeze, 1780 populations (Acari, Scutacaridae, Heterostigmatina). J Nat Hist 49:1173-1190. doi:10.1080/00222933.2014.974705

Kerschbaumer M, Postl L, Koch M, Wiedl T, Sturmbauer C (2011) Morphological distinctness despite large-scale phenotypic plasticity- analysis of wild and pond-bred juveniles of allopatric populations of Tropheus moorii. Naturwiss 98:125-134. doi:10.1007/s00114-010-0751-2

Lea DW, Pak DW, Belanger CL, Spero HJ, Hall MA, Shackleton NJ (2006) Paleoclimate history of Galápagos surface waters over the last 135,000 yr. Quat Sci Rev 25(11-12):1152-1167

Lehmitz R, Russel D, Hohberg K, Christian A, Xylander WER (2011) Wind dispersal of oribatid mites as mode of migration. Pedobiologia 54:201-207

Minto LB, Shepherd GJ, Usher MB (1991) The cryptostigmatid mite Halozetes belgicae (Michael) in the maritime Antarctic. Antarct Sci 3:53-59

Pfingstl T (2017) The marine-associated lifestyle of ameronothroid mites (Acari, Oribatida) and its evolutionary origin: a review. Acarologia 57(3):693-721

Pfingstl T, Jagersbacher-Baumann J (2016) Indications of parthenogenesis and morphological differentiation in Hawaiian intertidal Fortuynia (Acari, Oribatida) populations. Zool Anz 260:11-24

Pfingstl T, Schatz H (2017) New littoral mite species (Acari, Oribatida, Fortuyniidae) from the Galápagos archipelago, with ecological and zoogeographical considerations. Zootaxa 4244:39-64

Pfingstl T, Schuster R (2014) Global distribution of the thalassobiontic Fortuyniidae and Selenoribatidae (Acari, Oribatida). Soil Org 86:125-130

Schatz H (1991) Arrival and establishment of Acari on oceanic islands. In: Dusbabek F, Bukva F (eds) Modern acarology, vol 2. Academia. Prague and SPB Academic Publishing, The Hague, pp 613-618

Schatz H (1998) Oribatid mites of the Galápagos Islands-faunistics, ecology and speciation. Exp Appl Acarol 22:373-409

Schuster R (1989) Transoceanic distribution of air-breathing littoral mites. Prog Acarol 1:355-362

Sequeira AS, Lanteri AA, Scataglini MA, Confalonieri VA, Farrell BD (2000) Are flightless Galapaganus weevils older than the Galápagos Islands they inhabit? Heredity 85:20-29

Simkin T (1984) Geology of Galápagos. In: Berry RJ (ed) Evolution in the Galápagos Islands. Academic Press, London, pp 61-75

Stekolnikov AA, Klimov PB (2010) A revision of chiggers of the minuta species-group (Acari: Trombiculidae: Neotrombicula Hirst, 1925) using multivariate morphometrics. Syst Parasitol 77:55-69

Torres-Carvajal O, Barnes CW, Pozo-Andrade MJ, Tapia W, Nicholls G (2014) Older than the islands: origin and diversification of Galápagos leaf-toed geckos (Phyllodactylidae: Phyllodactylus) by multiple colonizations. J Biogeogr 41(10):1883-1894 